\title{
Investigating Evacuation Trends and Restoration Processes from Serious Earthquake Damage in Japan
}

\author{
Habib Sufian, Tatsuo Oyama \\ National Graduate Institute for Policy Studies (GRIPS), Roppongi, Minato-ku, Tokyo, Japan \\ Email: mep19111@grips.ac.jp, oyamat@grips.ac.jp
}

How to cite this paper: Sufian, H. and Oyama, T. (2021) Investigating Evacuation Trends and Restoration Processes from Serious Earthquake Damage in Japan. American Journal of Operations Research, 11, 35-61.

https://doi.org/10.4236/ajor.2021.111003

Received: November 12, 2020

Accepted: January 19, 2021

Published: January 22, 2021

Copyright $\odot 2021$ by author(s) and Scientific Research Publishing Inc. This work is licensed under the Creative Commons Attribution International License (CC BY 4.0). http://creativecommons.org/licenses/by/4.0/

\section{Open Access}

\begin{abstract}
Japan has experienced many large-scale natural disasters, such as earthquakes, typhoons accompanied by heavy rain, and landslides. Based on data for the damage caused by four recent major earthquakes in Japan, we investigate the trends in the number of evacuees and evacuation centres after these disasters as well as the restoration processes for public utilities such as electricity, gas, water, and communication lines. We compare the restoration speeds and trends of the damaged infrastructure systems. We also propose various mathematical models to approximate the recovery trends using both evacuee-related data and damage recovery process data. These results can be used to design natural disaster mitigation policies not only in Japan, but also in other countries. The results of various statistical data analyses and mathematical modelling techniques are applied to provide policy suggestions.
\end{abstract}

\section{Keywords}

Earthquake, Evacuees, Restoration Process, Statistical Data Analysis, Public Utilities, Mathematical Model, Social Infrastructure

\section{Introduction}

Japan is a nation that is highly vulnerable to disasters such as earthquakes, landslides, and tsunamis; it faces numerous disasters every year, resulting in losses to human life and the economy. Natural disasters affect millions of people every year with the mass destruction costing billions of dollars. Earthquakes, typhoons, and tsunamis have frequently struck Japan, and after every major catastrophe, people are left with damaged homes and severely damaged social infrastructure. The post-disaster restoration process has been a significant challenge 
for affected nations, as natural disasters, particularly earthquakes, are unpredictable with respect to time, location, and magnitude. As huge financial resources are required for the reconstruction and restoration of livelihoods, it has always been very difficult after natural disasters to restore the necessary infrastructure and attain the pre-disaster level of economic growth [1]. According to the International Disaster Database [2] (also cited in [3]), the number of natural disasters has significantly increased from 837 to 4939 worldwide between 19701979 and 2000-2012; 40.8\% of these disasters have occurred in Asia. Japan experiences numerous earthquakes, landslides, and other types of natural catastrophes because it is located on the Pacific earthquake belt, while its complex coastline is vulnerable to tsunamis and typhoons [4].

Japan experiences three or four earthquakes of magnitude 6.0 or greater every year [2]. The Hanshin-Awaji Earthquake (January, 1995) resulted in 6400 people being classified as either dead or missing. In March 2011, the Great East Japan Earthquake resulted in 16,000 deaths and 2800 missing people. Moreover, as a result of this earthquake, more than 320,000 evacuees still have not returned to their homes. The East South Sea Earthquake, which is predicted to occur in the near future, is expected to result in 25,000 dead or missing people, 960,000 damaged homes, and 50 trillion yen in economic losses. Moreover, earthquakes cause severe damage to public utilities such as electricity, gas, and water, which results in the interruption of services. This forces residents to evacuate to areas such as public schools and public halls, where they must often remain for long periods.

In recent years, Japan has experienced four major earthquakes: the Great Hanshin Awaji Earthquake ${ }^{1}$ (HNSA) in 1995, the Niigata-Chuetsu Earthquake ${ }^{2}$ (NGTC) in 2004, the Great East Japan Earthquake ${ }^{3}$ (GEJE) in 2011, and the Kumamoto Earthquake ${ }^{4}$ (KMMT) in 2016. These four recent major earthquakes resulted in severe damage. Major data for these earthquakes are listed in Table 1.

Table 1. Recent major earthquakes in Japan.

\begin{tabular}{ccccccc}
\hline EQ. & Date & Mw. & D \& M & Inj. & EV (Max) & EL (Yen) \\
\hline HNSA & 1995.01 & 7.3 & $6434(3)$ & 43,792 & 316,678 & $10 \mathrm{TY}$ \\
NGTC & 2004.10 & 6.8 & 68 & 4805 & $100 \mathrm{~T}$ & $3 \mathrm{TY}$ \\
GEJE & 2011.03 & 9.0 & $19.689(2563)$ & 6233 & $100 \mathrm{~T}$ & $16-25 \mathrm{TY}$ \\
KMMT & 2016.04 & 7.0 & 273 & 2809 & 183,882 & $4.6 \mathrm{TY}$ \\
\hline
\end{tabular}

Mw.: Magnitude, D \& M: Deaths and missing, Inj.: Injured, EV: Evacuees, T: Thousand, EL: Estimated losses, TY: Trillion yen.

1https://ja.wikipedia.org/wiki/\%E9\%98\%AA\%E7\%A5\%9E\%E3\%83\%BB\%E6\%B7\%A1\%E8\%B7\%AF \%Е5\%A4\%A7\%E9\%9C\%87\%E7\%81\%BD.

${ }^{2}$ https://ja.wikipedia.org/wiki/\%E6\%96\%B0\%E6\%BD\%9F\%E7\%9C\%8C\%E4\%B8\%AD\%E8\%B6\%8A \%Е5\%9C\%B0\%Е9\%9C\%87.

${ }^{3}$ https://ja.wikipedia.org/wiki/\%E6\%9D\%B1\%E6\%97\%A5\%E6\%9C\%AC\%E5\%A4\%A7\%E9\%9C\%87 \%E7\%81\%BD.

${ }^{4}$ https://ja.wikipedia.org/wiki/\%E7\%86\%8A\%E6\%9C\%AC\%E5\%9C\%B0\%E9\%9C\%87_(2016\%E5\%B $\underline{9 \% \mathrm{~B} 4)}$. 
In Table 1, EV (Max) indicates the maximum number of evacuees at the peak time, and EL (Yen) indicates the estimated economic losses due to the earthquake damage. Using data regarding deaths and missing people, evacuees and evacuation centres, water supply suspension and restoration, and other parameters, we applied statistical data analysis techniques to investigate these earthquakes with various corresponding mathematical models in order to develop more desirable and efficient mitigation policies for natural disaster preparation in Japan.

Among these earthquakes, the GEJE, which was followed by a tsunami, was the deadliest disaster; it was the world's third-strongest earthquake since 1900 . The Cabinet Office of Japan estimated the overall losses caused by this earthquake at 16.9 trillion yen [5]. Such disastrous events adversely affect citizens' lives, as basic utilities such as electricity, water, and gas supplies are suspended owing to severely damaged infrastructure. Victims are thus forced to stay in evacuation centres until the recovery of social infrastructure and basic utility services, which may take several months. Generally, local elementary and high schools are designated as evacuation centres after large-scale earthquakes.

Among other utility services, electricity and water supply systems are of vital importance for the health and development of any society, and these need to be adequately provided without interruption. Failure of the electric power supply after natural disasters may adversely affect societal and economic growth. Similarly, fire can break out and envelop both industrial and residential sectors on a wide scale, which cannot be combated if there is a failure of the water supply system after the occurrence of natural disasters. Because these social infrastructure systems are interdependent, damage to one public utility system may lead to the failure of other social infrastructure systems. Therefore, we aim to use various mathematical models to investigate recovery trends and describe the post-disaster restoration process. First, a damage analysis is conducted in terms of evacuees and evacuation centres, and the restoration of public utilities damaged by natural disasters is then examined. The public utilities under study include electricity, gas, telecommunication lines, and water supply systems to end-users.

Among the four recent major earthquakes, HNSA occurred in the most urban area, encompassing large cities such as Kobe and Osaka, while the others occurred in more locally remote areas. In particular, the most serious disaster, the GEJE, occurred in the remote Tohoku (Northeast) area in Japan. In the GEJE, three of the seriously damaged prefectures-Iwate, Miyagi, and Fukushimawere rather unpopulated areas, except that Miyagi has a large capital city, Sendai. Various quantitative studies have examined the process of infrastructure recovery in post-disaster scenarios using recovery-associated parameters to describe the recovery trends in disaster-affected regions. For example, major factors affecting human casualties of natural disasters were investigated and the recovery policies in Japan were also reviewed [6]. In addition, they applied statistical data analysis to compare historical earthquake and tsunami disasters in Ja- 
pan and Indonesia. In addition, network flow optimisation techniques to improve transport strategies for relief goods under emergency situations were applied [7]. The impact of the 2011 GEJE and evaluated the subsequent restoration and reconstruction performance was investigated [8].

A cumulative normal distribution approach was used to compare the recovery curves for housing reconstruction after the GEJE with those of other historic disasters [9]. That study focused on solving problems related to the recovery of urban housing by comparing strategies and policies for both recovery and post-disaster planning. The time for infrastructure restoration was estimated by combining 63 recovery curves for electricity, water, gas, and telecommunication systems collected from 19 past disaster events to establish a global mean [10]. Similarly, regression model was employed with covariates to investigate the recovery rates of social infrastructure [11]. This methodology was based on various influencing factors, as covariates and past data were used to estimate the recovery rate. However, to date, no studies have investigated the recovery trends for water supplies and other utility services damaged during large-scale earthquakes in Japan.

Japan is a disaster-prone country as it experiences floods, landslides, earthquakes, typhoons, and tsunamis due to its geographical, topographical, and meteorological conditions; as a result, the water supply can be severely disrupted [12]. Therefore, it is important to develop performance indicators (PIs) to measure the robustness of the water supply quantitatively before and after disasters. This can provide future strategic planning to avoid neglected areas and strengthen the disaster mitigation policy in Japan.

This study investigates the trends in the number of evacuees and evacuation centres after the occurrence of disasters and explores the restoration processes of public utilities such as electricity, water, gas, and telecommunications. Then, we investigate the recovery trends of these utilities after major earthquakes in Japan. First, to determine the degree of devastation, a damage analysis is conducted for each earthquake by considering evacuees and evacuation centres. Second, the recovery of social infrastructure such as electricity, gas, and telecommunication lines in urban areas is analysed after the earthquakes. Finally, the recovery process of the water supply system is analysed after the occurrence of large-scale earthquakes. Basic statistical techniques are employed to examine the recovery rate of the water supply system after four major historical earthquakes in Japan. The various data for the analyses are obtained from the official webpages of the relevant ministries and prefectural governments in Japan. In Section 2, we investigate the trends in the number of evacuees and evacuation centres for recent major earthquakes in Japan. In Section 3, we describe the suspension and restoration processes of social infrastructure, including electricity, gas, water, and communication lines. Section 4 focuses on the recovery of the water supply by applying regression analyses to the water supply disruption data from HNSA, NGTC, KMMT, and GEJE to measure the recovery rates of water supply systems in different regions after large-scale earthquakes. Finally, in Section 5, we sum- 
marise the findings and conclude with some policy recommendations.

\section{Trend Analyses for Evacuees and Evacuation Centres}

We conduct a damage analysis by correlating the number of evacuees with the evacuation centres. First, the changes in the numbers of both evacuees and evacuation centres following major earthquakes in Japan are analysed. The data for evacuees and evacuation centres are plotted after the occurrence of the earthquakes to estimate the degree of damage. Next, the data for evacuees and evacuation centres in each of the major earthquakes are investigated with respect to time after the occurrence of the disaster to develop a mathematical model that describes the rate of decrease in the number of evacuation centres.

Figure 1 and Figure 2 show the decreasing patterns of the evacuation centres (EVCN) and evacuees (EVCU), respectively, after the occurrence of four major earthquakes in Japan. In these figures, "D" and "M" on the horizontal axis indicate the day and month, respectively. The data are obtained from the webpages of relevant prefectural and municipal governments [13]-[18], and the homepage of the National Police Agency of Japan. EVCN is located on the horizontal axis, while EVCU is on the vertical axis. It can be observed that EVCN and EVCU reach an initial peak and then decrease gradually with time after the HNSA, NGTC, and KMMT earthquakes. However, the GEJE does not follow this pattern, as the EVCN increases over time, with nearly 1500 centres open even after three months. This unusual trend is mainly due to the nuclear disaster at the Fukushima Nuclear Power Plant caused by the powerful earthquake followed by a tsunami in March 2011.

Figures 3-5 show the trends in the relationship between EVCN and EVCU for the HNSA, NGTC, and KMMT earthquakes, respectively. In these figures, dotted

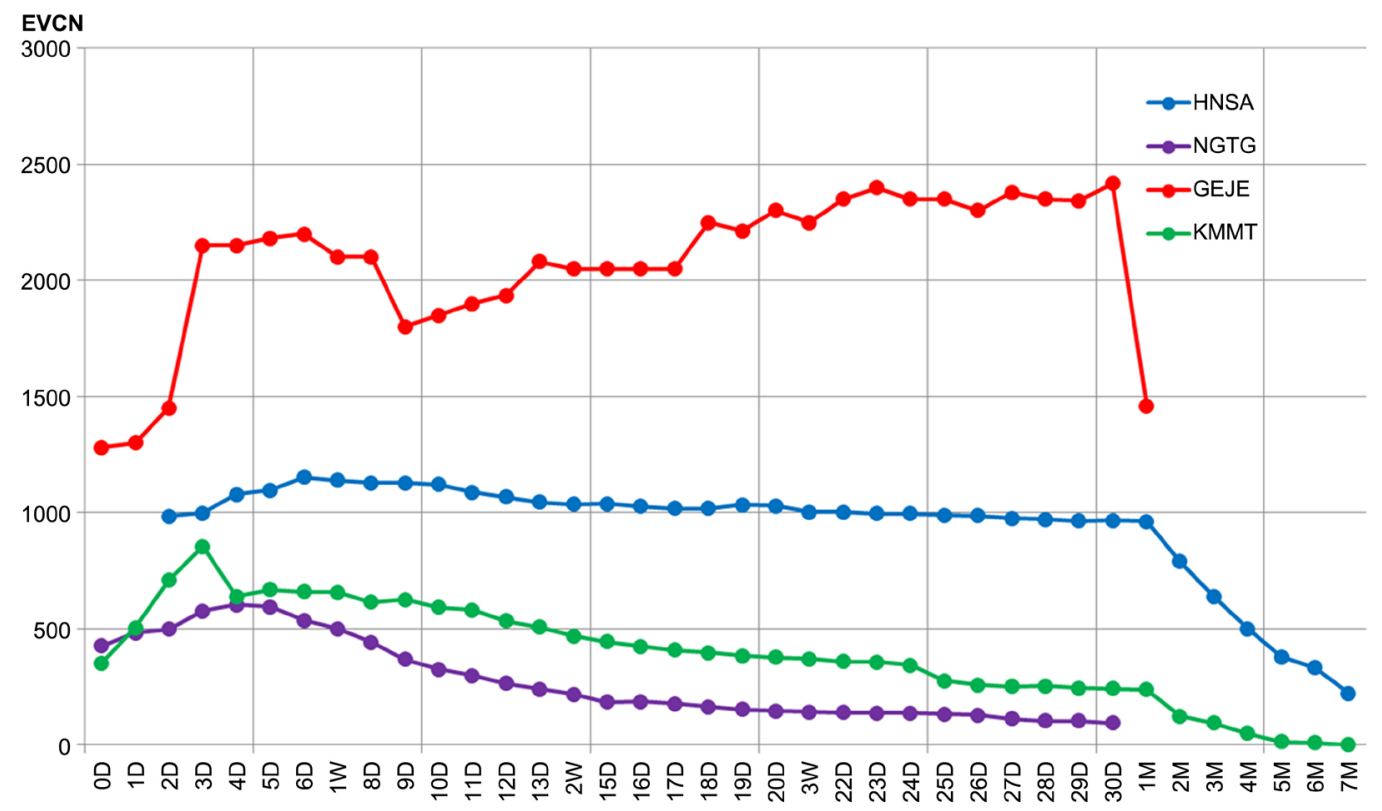

Figure 1. Trends in evacuation centres after major earthquakes in Japan. 


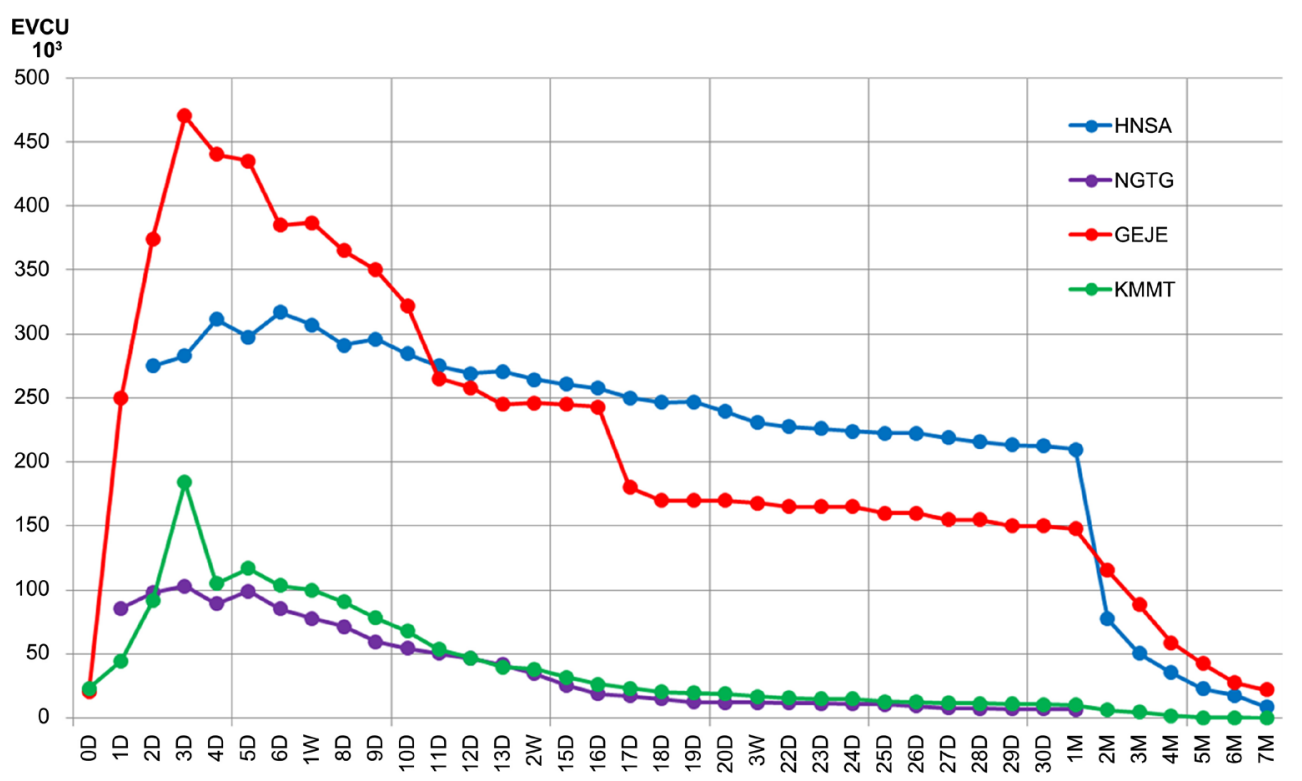

Figure 2. Trends in the number of evacuees after four major earthquakes in Japan.

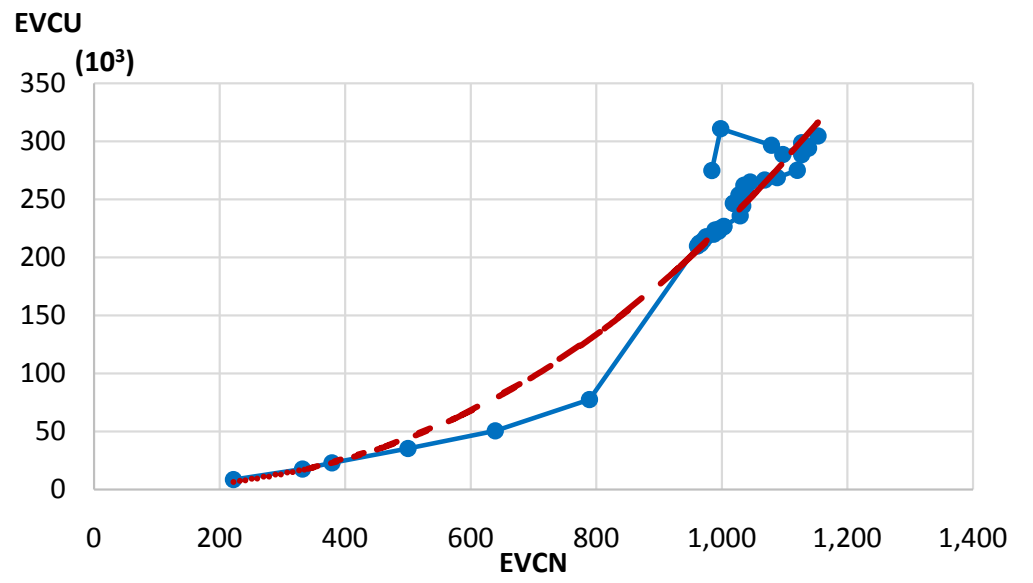

Figure 3. Relationship between EVCN and EVCU (HNSA) (Data source: [14] [15]).

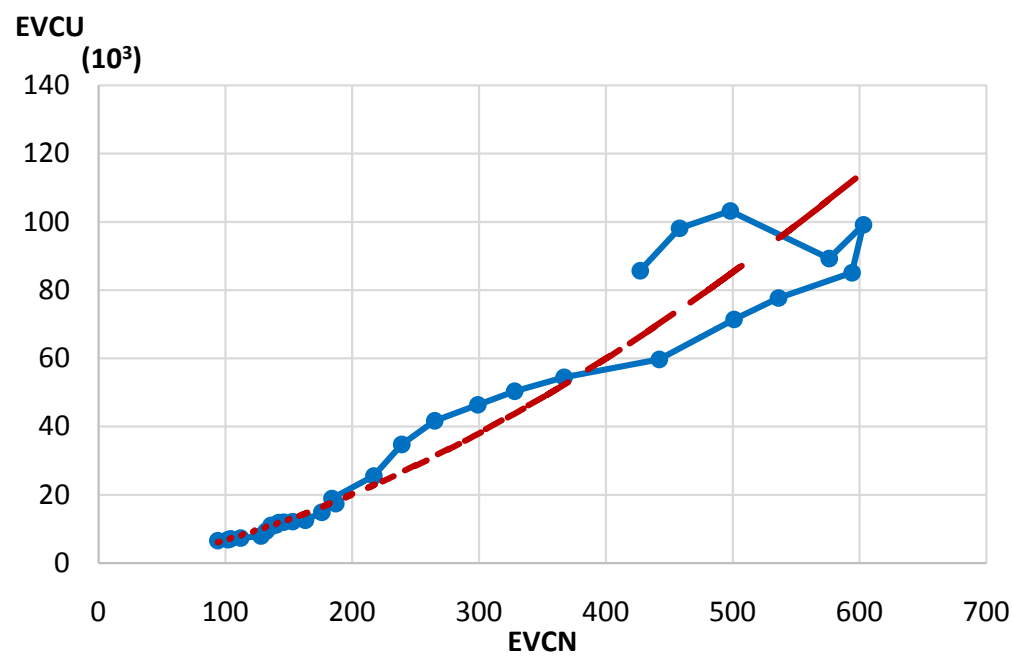

Figure 4. Relationship between EVCN and EVCU (NGTC) (Data source: [16]). 


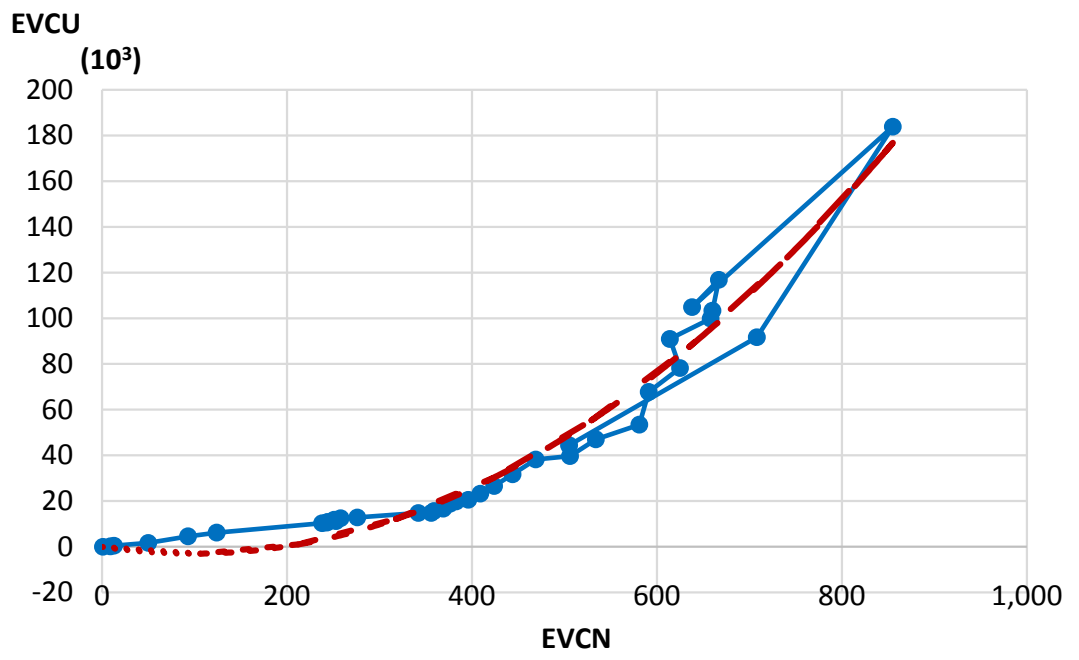

Figure 5. Relationship between EVCN and EVCU (KMMT) (Data source: [17]).

lines indicate approximation curves fitted to the actual data. On 17 January 1995, one of the deadliest earthquakes (with a magnitude of greater than 7.0 on the Japan Meteorological Agency (JMA) scale) in the history of Japan hit Kobe city and other southern parts of Hyogo prefecture. It was the worst seismic disaster since the Great Kanto earthquake of 1923. Apart from the collapsed public infrastructure, the HNSA earthquake created more than 300,000 evacuees as a result of 240,000 damaged homes. The evacuation situation after the HNSA earthquake is plotted in Figure 1 and Figure 2. The maximum number of evacuees was reported on the third day (represented by 3D) after the disaster, as shown by the horizontal dashed line. Moreover, it required approximately 4.5 months for the number of evacuees to decrease to $10 \%$ of the maximum number. The HNSA is shown graphically in Figure 3 with its approximation curve. The evacuation situation in terms of the relationship between EVCN and EVCU for each day or month after the HNSA earthquake is shown in Figure 3, in which the dotted curve indicates an approximation of the original data. In Figure 3 , the time trend of data moves from large EVCNs, corresponding to the earlier stage after the disaster occurrence, to small ones, for which the general trend approximately follows the dotted curve although in the early stage data show fluctuating moves.

In the NGTC earthquake, the Niigata prefecture of Japan was jolted by three powerful earthquakes (with magnitudes of greater than 6.2 on the JMA scale) that occurred within $40 \mathrm{~min}$ on 23 October 2004. The epicentre of the earthquake was Ojiya city in Niigata prefecture. In spite of the moderate intensity, the earthquake was regarded as destructive because of its shallow focal depth, resulting in pervasive landslides causing severe damage throughout the region. The maximum number of evacuees after the NGTC occurred on the third day, represented by $3 \mathrm{D}$. The trend shows a reduction to $10 \%$ of the maximum at $25 \mathrm{D}$ after the earthquake. The relationship between EVCN and EVCU after the NGTC earthquake is shown in Figure 4. 
In the KMMT earthquake, Kumamoto prefecture was shattered by a wave of two powerful earthquakes of magnitude 7 (JMA scale) on 14 and 16 April 2016, with the worst damage ever recorded. As per report \#119 issued on 11 July 2016 by the Kumamoto Prefecture Disaster Response Headquarter 8241 buildings collapsed completely and 25,663 were partially damaged [17]. From Figure 5, we see that the maximum number of evacuees $(183,882)$ occurred on $3 \mathrm{D}$. This was reduced to $10 \%$ at $20 \mathrm{D}$ after the earthquake.

In Figures 3-5, we indicate the approximation curves as dotted lines for each set of actual data points. The mathematical models of these relationships can be expressed generally by the following polynomial function.

$$
y=\sum_{i=0}^{n} a_{i} x^{b_{i}}
$$

$x$. number of evacuation centres (hundreds) (EVCN).

$y$. number of evacuees (thousands) (EVCU).

In Equation (1), $a_{i}$ and $b_{i}$ for $i \in N=\{1,2, \cdots, n\}$ are parameters. Applying the least squares method to estimate the parameters for the datasets in Figures 3-5, we obtain the results given in Table 2.

From the results in Table 2, the approximate functions for the HNSA and NGTC earthquakes are expressed as follows.

$$
y=a x^{b}, a, b: \text { parameters. }
$$

In the above Equation (2), parameter $a$ and $b$ can be interpreted as an initial volume of the data and the elasticity of $y$ with respect to $x$. Transforming the above equation, we can estimate the parameters using the following equation.

$$
\log y=\log a+b \log x
$$

Thus, parameter $b$ indicates the elasticity of variable $y$ with respect to $x$, implying the $\%$ increase (or decrease) in variable $y$ corresponding to a $1 \%$ increase (or decrease) in variable $x$.

$$
\left(\frac{\mathrm{d} y}{y}\right) /\left(\frac{\mathrm{d} x}{x}\right)=b
$$

From the results given in Table 2, we see that the values of parameter $b$ are 2.360 and 1.580 for HNSA and NGTC, respectively. Thus, we find that the recovery

Table 2. Regression results for mathematical models.

\begin{tabular}{ccccc}
\hline E.Q. & HNSA & NGTC & KMMT & TOTAL \\
\hline Model & $y=a x^{b}$ & $y=a x^{b}$ & $y=a x^{2}+b x$ & $y=a x^{2}+b x$ \\
\hline \multirow{2}{*}{$a$} & 0.0189 & 4.632 & 0.3139 & 0.2357 \\
& $(8.471)$ & $(5.799)$ & $(16.23)$ & $(24.03)$ \\
& $(0.0)$ & $(0.0)$ & $(0.0)$ & $(0.0)$ \\
& 2.269 & 1.580 & -61.52 & 2.114 \\
$b$ & $(34.27)$ & $(32.72)$ & $(-5.389)$ & $(0.2293)$ \\
& $(0.0)$ & $(0.0)$ & $(0.0)$ & $(0.819)$ \\
$R^{2}$ & 0.9719 & 0.9730 & 0.9505 & 0.9783 \\
\hline
\end{tabular}


speed for HNSA was faster than that for NGTC. In the case of KMMT, we obtain the following approximation expression from the quadratic function.

$$
y=a x^{2}+b x \quad a, b: \text { parameters }
$$

Differentiating the above formula with respect to $x$, we obtain the following.

$$
\frac{\mathrm{d} y}{\mathrm{~d} x}=2 a x+b \quad a, b: \text { parameters }
$$

From the above expression, we can determine that when the number of evacuation centres decreases by 1 (unit amount) from EVCN values of 500 and 200, the decrease in the EVCU value obtained from (6) would be approximately 252 and 64, respectively. This implies that the decrease in EVCU with a unit reduction in EVCN is much larger when EVCN is greater.

The GEJE was a devastating disaster that occurred in the Tohoku region on 11 March 2011, with a seismic intensity of greater than 9.0 on the JMA scale. A huge tsunami occurred after the earthquake, which demolished the east coast of Japan, including Iwate, Miyagi, and Fukushima. The tsunami also caused severe damage to the FDNPP (Fukushima Dai 1 Nuclear Power Plant), resulting in electric power failure and subsequent explosion of the plant. The government requested that residents living within a radius of $20 \mathrm{~km}$ evacuate their homes to avoid harm from the nuclear radiation released by the explosion. Most of these evacuees remained unable to return to their homes even after four months.

Unlike Figures 3-5 that exhibit a gradual decrease in the EVCU and EVCN over time, Figure 6 shows an irregular pattern after including the trend of the GEJE. Compared with the evacuation situations after the HNSA, NGTC, and KMMT earthquakes, Figure 6 shows an entirely disparate trend for the GEJE, with nearly 1500 evacuation centres even after a lapse of three months. This is mainly due to the nuclear disaster at the FDNPP caused by the earthquake and subsequent tsunami. Because the GEJE was an oceanic plate earthquake accompanied by a huge tsunami, its trend in Figure 6 is significantly different from those of the other three large-scale earthquakes. However, interestingly, we find that the trend for the GEJE, as shown in Figure 6, returns to near the points on the "approximation curve" for the other major earthquakes about three months after its occurrence.

A comparison of the evacuation situations in the three major earthquakes, excluding the GEJE, is shown in Figure 6. Using the data for the HNSA, NGTC, and KMMT major earthquakes, we can find an approximation curve with the polynomial quadratic form given in Equation (5). The results of the corresponding parameter estimates are given in the TOTAL column in Table 2, and a plot of the original data and the approximation curve (the dotted curve) is shown in Figure 7.

It can be observed that HNSA was the most destructive earthquake, followed by KMMT and NGTC, in terms of the number of evacuees. In terms of damage, HNSA peaked with 310,862 evacuees in 998 evacuation centres, whereas the peak evacuation situations after the KMMT and NGTC earthquakes comprised 


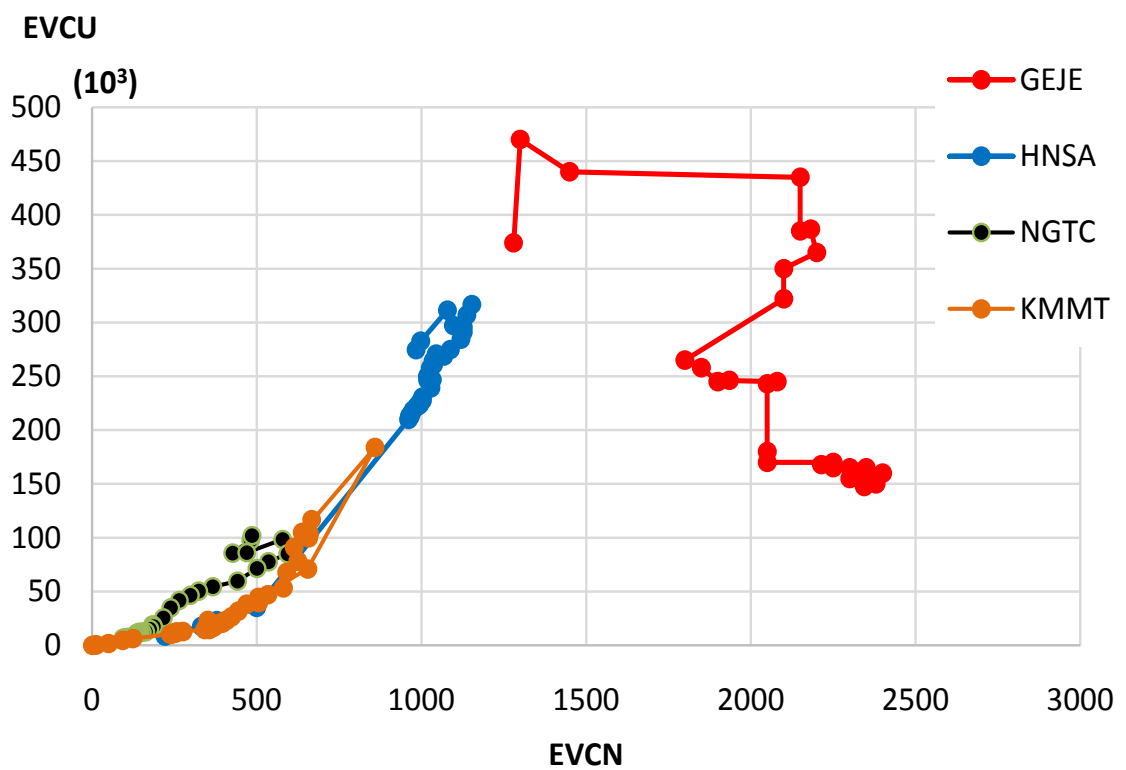

Figure 6. Trends in EVCN and EVCU (HNSA, NGTC, KMMT, and GEJE).

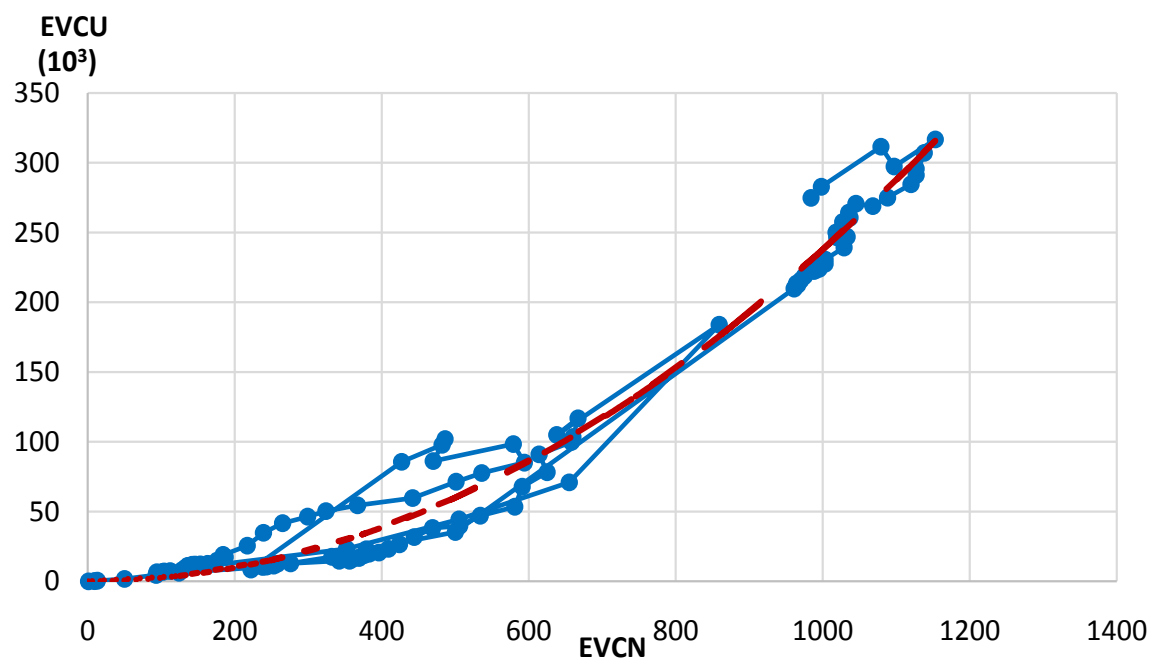

Figure 7. Trend in EVCN vs. EVCU and the corresponding approximation curve (HNSA, NGTC, and KMMT).

183,822 and 103,178 evacuees staying in 855 and 498 evacuation centres, respectively. Although there is a difference in scale, the three earthquakes have similar evacuation trends. Nevertheless, the rate of decline in the number of evacuation centres was more significant for HNSA than NGTC and KMMT. Moreover, it can be observed that EVCU and EVCN peaked initially, after which both variables gradually approached the origin $(0,0)$.

\section{Suspension and Restoration Processes for Social Infrastructure}

We investigated the suspension and restoration processes for social infrastructure following four major earthquakes: the HNSA earthquake (17 January 1995), 
the NGTC earthquake (23 October 2004), the GEJE (11 March 2011), and the KMMT earthquake (14 April 2014).

Table 3 indicates the number of households (HHs) with suspended public utilities including electricity, gas, water supply, and communication lines, and the number of days required to restore these services in Kobe city following the HNSA earthquake. Electricity was restored first, in six days, followed by communication lines in two weeks; the gas and water supplies required almost three months for restoration. These trends were similar for all of the studied natural disasters. Therefore, we aimed to shorten the restoration period for the gas and water supplies, considering that restoration even a few weeks earlier would be extremely beneficial. In addition, we considered that the restoration trend curves differ among the public utilities. In particular, the electricity and water supply exhibited convex forms, whereas the gas supply and communication lines were rather concave. Moreover, the gas supply sometimes produced a convex-to-concave trend with a convex trend followed by a concave trend. Therefore, these properties need to be considered when developing natural disaster mitigation policies.

Table 3 reveals the restoration trends for public utilities such as water, gas, electricity, and communication lines following the HNSA earthquake.

Table A1 in the Appendix summarises the restoration trends for electricity, water supply, gas, and communication lines for the HNSA earthquake. Corresponding to the data in Table A1, Figure 8 and Figure 9 show both the actual data and approximation curves for the electricity and water supply, respectively. The approximation curves for the restoration processes are shown as dotted lines.

For the electricity restoration shown in Figure 8, we obtain the approximation function in the form of Equation (2). Using the transformation given in Equation (3), we can estimate the parameters from Table 3.

The parameter estimates for $a$ and $b$ corresponding to the restoration of the electricity and water supply are listed in Table 4 . As seen in Figure 8 and Table 4 , we find that the approximation curve is accurate with high adj. $R^{2}$ value. Thus, the restoration of electricity in Kobe can be given by the following mathematical model:

$$
y=2.589 x^{-2.726} .
$$

Immediately after the HNSA earthquake, the water supply was cut off in

Table 3. Suspension and restoration of public utilities (HNSA).

\begin{tabular}{ccc}
\hline Public utility & Suspension & Days required for restoration \\
\hline Electricity & $2600 \mathrm{HH}$ & 6 \\
Gas & $855.9 \mathrm{HH}$ & 84 \\
Water & $495.3 \mathrm{HH}$ & 90 \\
Communication lines & $101.66 \mathrm{LN}$ & 14 \\
\hline
\end{tabular}

HH: Households (unit: 1000 homes); LN: lines. 
Table 4. Parameter estimates for the electricity and water supply restoration models.

\begin{tabular}{|c|c|c|c|}
\hline \multirow{2}{*}{ Parameter } & Electricity & \multirow{2}{*}{ Parameter } & \multirow{2}{*}{$\begin{array}{c}\text { Water supply } \\
\text { Disrupted HHs }\end{array}$} \\
\hline & Disrupted HHs & & \\
\hline \multirow{3}{*}{$\log a$} & 5.5902 & & -141.47 \\
\hline & $(28.93)$ & $a$ & $(47.067)$ \\
\hline & $(0.00)$ & & $(0.00)$ \\
\hline \multirow{3}{*}{$b$} & -2.7261 & & 600.1533 \\
\hline & $(17.668)$ & $b$ & $(56.80)$ \\
\hline & $(0.00)$ & & $(0.00)$ \\
\hline $\operatorname{adj} . R^{2}$ & 0.9842 & $R^{2}$ & 0.9664 \\
\hline$n$ & 5 & $n$ & 77 \\
\hline
\end{tabular}

adj. $R^{2}$ : adjusted $R^{2} ; n$ : number of data points; figures in parentheses indicate the $t$-value (upper) and $P$-value (lower).

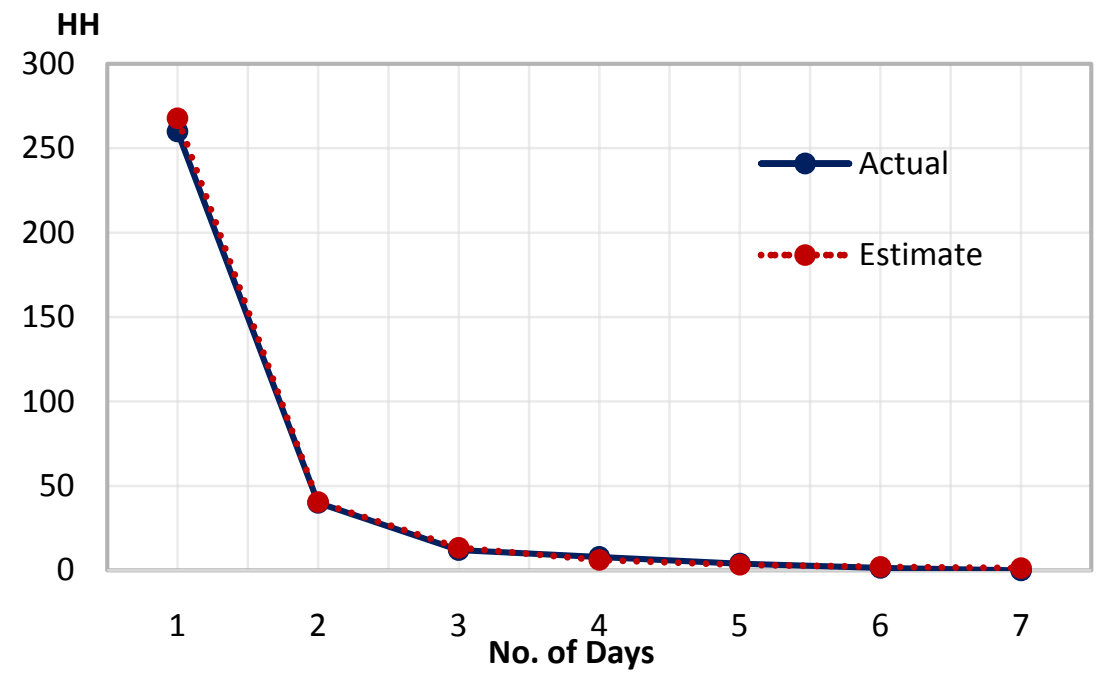

Figure 8. Electricity restoration trend and approximation curve (HNSA).

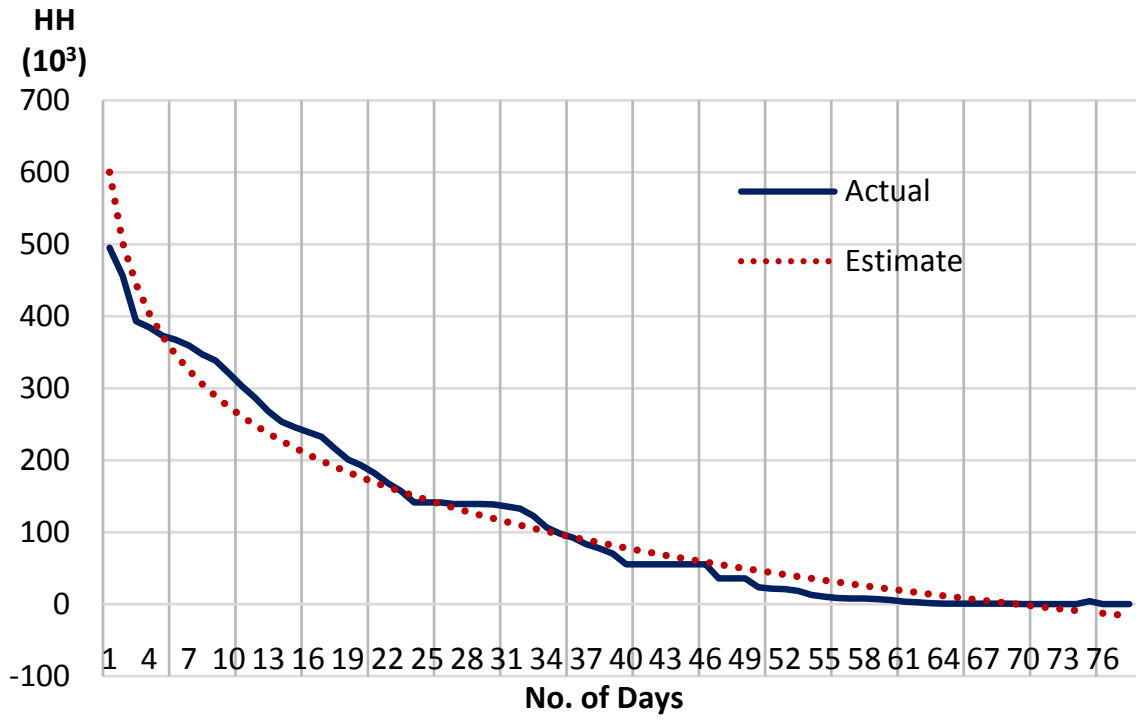

Figure 9. Water supply restoration trend and approximation curve (HNSA). 
$1,265,730 \mathrm{HHs}$ in 10 cities and 7 towns. This corresponded to almost $90 \%$ of the total number of $\mathrm{HHs}$ in these areas. Moreover, in 5 cities and 4 towns, including the major cities of Kobe, Nishinomiya, and Ashiya, all of the HHs experienced disrupted water supplies. However, the restoration was very rapid in these areas, with the water restored in one town the day of the incident, in one city and one town the next day, and in two cities and four towns within a week. After one week, the percentage of $\mathrm{HHs}$ with a suspended water supply was $45.1 \%$, which is almost half those that were without water on the first day. After two weeks, the total was $3.2 \%$, indicating that the water supply had been restored in almost all HHs. In the entire Hyogo prefecture, the percentage of HHs with a suspended water supply was $33.7 \%$. We used these statistical data to develop various types of mathematical models to evaluate their relationships and processes. The mathematical model expressing the approximation function for the restoration of the water supply can be given in the form of the following nonlinear function:

$$
y=a \log x+b \quad a, b \text { : parameter. }
$$

Therefore, as shown in Figure 9, the restoration process for the disrupted water supply to Kobe $\mathrm{HHs}$ can be described using the following mathematical model:

$$
y=-141.47 \log x+600.15
$$

Figure 8 and Figure 9 show that the actual and estimated values for the restoration of both the electricity and water supply are in good agreement. In Figure 8, we see that the actual and estimated values coincide. In Figure 9, the number of HHs with a disrupted water supply becomes zero when $y=-141.47 \log x+600.153=0$, i.e. when $x=\exp (4.243)=69.57$. Thus, the number of HHs with a disrupted water supply becomes zero almost $70 \mathrm{~d}$ after the occurrence of the disaster.

Figure 10 shows the trend in the number of $\mathrm{HHs}$ with a disrupted water supply following the HNSA earthquake. The figure shows that almost 1.3 million HHs

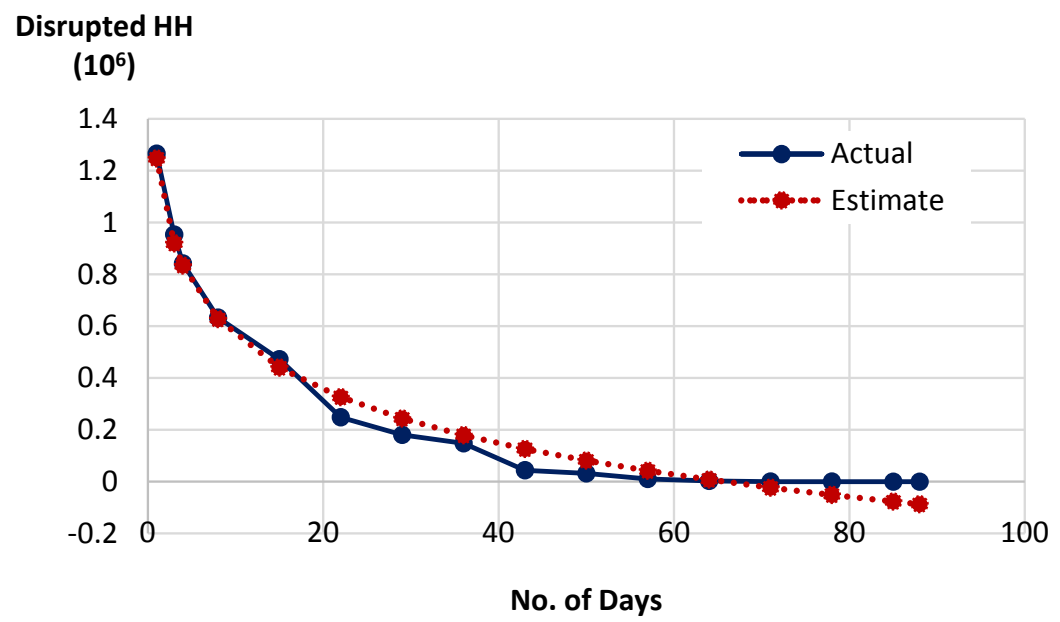

Figure 10. Trend in the number of HHs with a disrupted water supply following the HNSA earthquake. 
were disrupted. The restoration speed was very fast during the first month after disruption. However, after that period, two to three months were required for the water supply to be restored in all HHs.

In Figure 11 and Figure 12, we show the restoration trend data of the gas supply and communication lines, respectively. In these figures, actual data corresponding to $x$ and $y$ axes were proportionally transformed into the range between 0 and 1. Namely, for both horizontal and vertical coordinates, the total number of the days needed to restore and the total number of disrupted HHs by the incident correspond to 1.0, respectively. Thus, Figure 11 and Figure 12 show

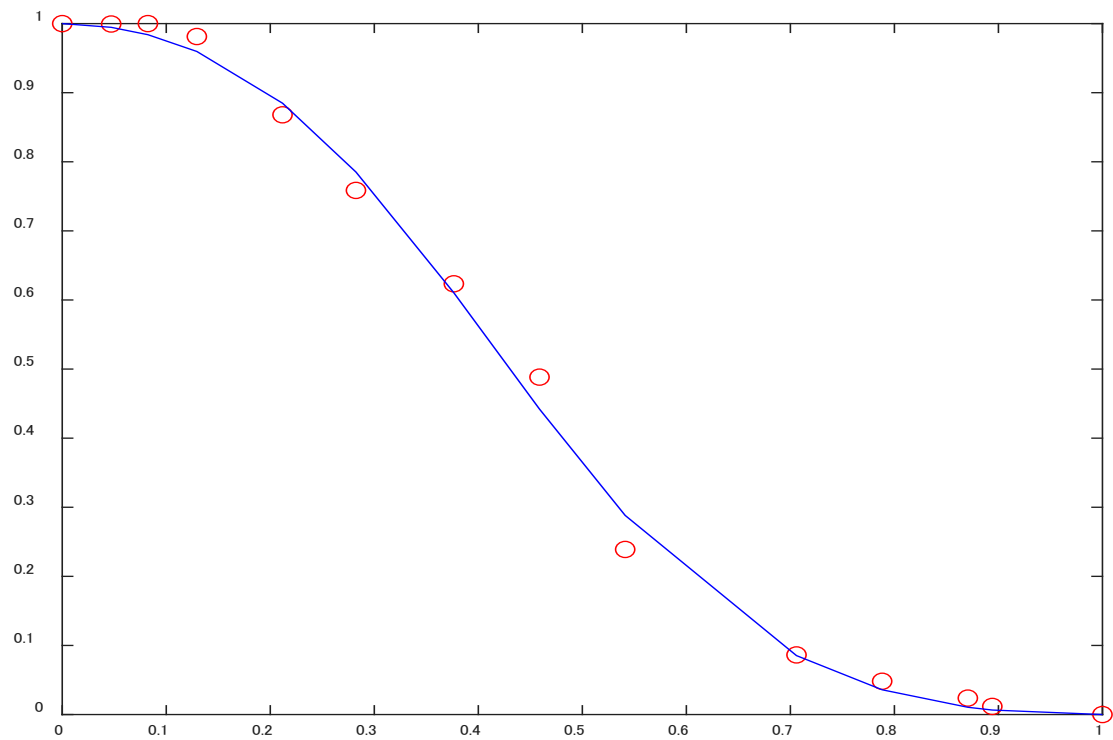

Figure 11. Gas supply restoration trend and its approximation as a survivability function (HNSA).

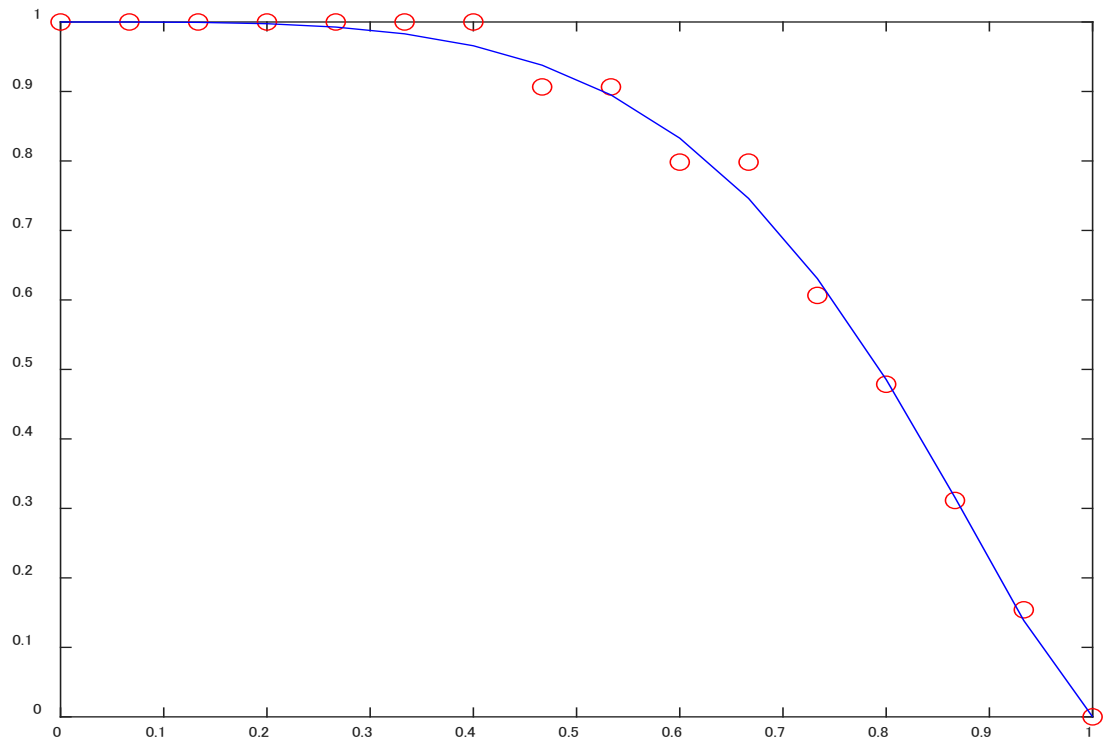

Figure 12. Communication line restoration trend and its approximation as a survivability function (HNSA). 
the restoration trends and approximation curves for HHs with disruptions in their gas supply and communication lines, respectively, following the HNSA earthquake in 1995. These figures show that the approximation curves for these restoration processes begin to decrease from the maximum of 1.0 with a concave form in the early stage, and then in approach 0.0 in the final stage with a concave form. Thus, for both the gas supply and communication line restoration, we assume that the approximation curves can be expressed by the following function, which is referred to as a survivability function. Table 5 lists the regression results and the parameter estimates for the survivability function in Equation (5) with a high goodness of fit.

$$
f(x)=\frac{\left(1-x^{p}\right)^{q}}{x^{p q}+\left(1-x^{p}\right)^{q}} \quad p, q: \text { parameter. }
$$

Incidentally, we have found that this survivability function has many applications in the analysis of social systems.

From Figure 11 and Figure 12, we can see that for the telecommunication lines, no restoration was observed in the first six days after the occurrence of the earthquake, although they were completely restored after fifteen days. Similarly, a negligible restoration of the gas lines was observed during the first ten days after the occurrence of the disaster, followed by notable progress after 1.5 months. However, the restoration trend fell considerably in the last month before complete restoration, as shown by the relatively flatter curve in Figure 12 .

Social infrastructure includes electricity, the water supply, the gas supply, and communication lines. According to the analyses above, the restoration processes can be divided into two types. The first group consists of electricity and water, which exhibit convex restoration curves. The second group includes the gas supply and communication lines, which have the form of a concave function or a concave function following a convex curve. Thus, from the viewpoint of public policy focusing on natural disaster mitigation, for electricity and water systems, increasing the slope of the decreasing curve is important, whereas for gas and communication lines, shortening the initial flat part of the curve before the decreasing portion is more important.

\section{Disruption and Restoration Processes for the Water Supply System}

We investigated the restoration trends for water supply systems following four

Table 5. Parameter estimates for the survivability functions.

\begin{tabular}{ccc}
\hline Param. & Gas & Comm. \\
\hline$p$ & 0.8222 & 3.0026 \\
$q$ & 2.1489 & 1.2438 \\
$R^{2}$ & 0.9971 & 0.9956
\end{tabular}

Param.: Parameter, Comm.: Communication lines. 
major earthquakes in Japan. Generally, the water supply system includes raw water collection, water treatment facilities, pumping stations, storage tanks, and distribution systems for end-users. Figure 13 shows the water supply restoration curves in various prefectures affected by four recent major earthquakes in Japan. Data were adapted from the official webpages of the relevant prefectural governments and the MHLW of Japan (refer to [14] [15] [16] [17]). It is clear in the graphical representation that the recovery of disrupted HHs was fastest in the first month after the occurrence of a disaster, followed by a relatively slower restoration pattern. In a few cases, after one month, a sudden increase in the number of disrupted HHs can be observed, as for the GEJE. This is due to the aftershocks of the GEJE that occurred on 7 April and 11 April in coastal prefectures such as Iwate, Miyagi, and Fukushima, which caused a sudden rise in the number of disrupted HHs. It can be observed that the situation in almost all cases started to return to normal approximately one and a half months after the earthquakes.

The water disruption in Hyogo prefecture as a whole after the HNSA earthquake in 1995 (data in Table A2 in the Appendix) is shown in Figure 14 (refer to [19]). On the day of the HNSA earthquake, water supply services to nearly one million HHs were disrupted; however, the restoration process began the day after the earthquake, and the number of disrupted HHs approached zero after three months. In Figure 14, the approximation function is obtained by applying the form given in Equation (3) to the whole period of D1 - D90. Thus, the approximation function for the HNSA dataset can be expressed as follows:

$$
y=-259.22 \ln x+1088.50
$$

It can be observed from Equation (11) that the number of disrupted HHs becomes zero when $y=1.088-0.259 \ln x=0$, i.e. when $x=66.68$, which implies that the number of disrupted HHs becomes zero at approximately D67. The regression results for the restoration of the water supply after the HNSA earthquake are given in Table 6.

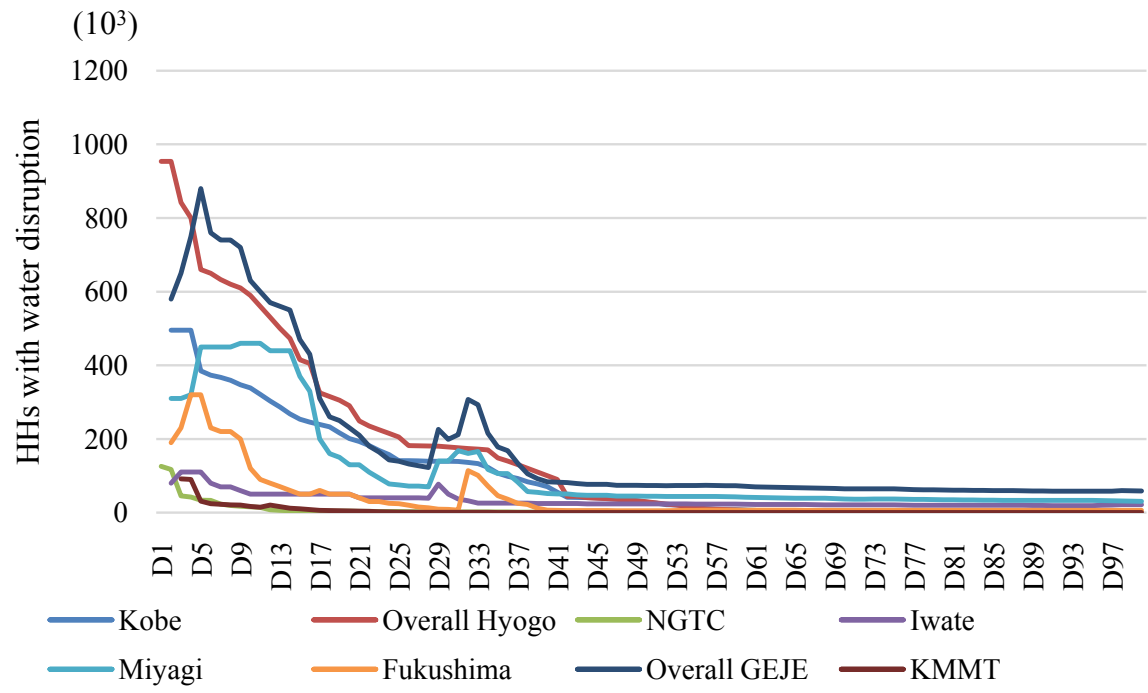

Figure 13. Water disruption after the four earthquakes. 


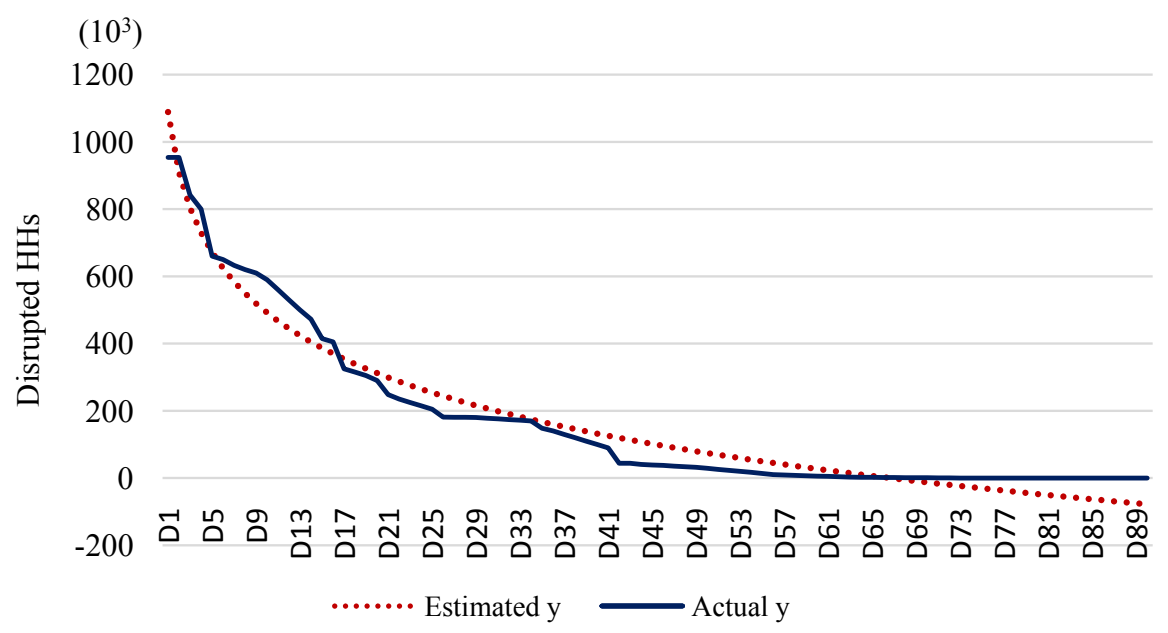

Figure 14. Disrupted HHs in Hyogo prefecture (HNSA).

Table 6. Parameter estimates for the water supply restoration models (HNSA, NGTC).

\begin{tabular}{ccccc}
\hline E.Q. & HNSA & E.Q. & \multicolumn{2}{c}{ NGTC } \\
\hline Model & $y=a \ln x+b$ & Model & \multicolumn{2}{c}{$y=a \mathrm{e}^{-b x}$} \\
\hline Period & D1 - D90 & Period & D1 - D14 & D14 - D41 \\
\hline \multirow{2}{*}{$a$} & 1088.50 & & 11.760 & 9.2326 \\
& $(52.84)$ & $a$ & $(100.38)$ & $(330.19)$ \\
& $(0.0)$ & & $(0.0)$ & $(0.0)$ \\
$b$ & -259.22 & & -0.2279 & -0.5227 \\
& $(-45.96)$ & $b$ & $(-16.56)$ & $(-53.58)$ \\
adj. $R^{2}$ & $(0.0)$ & & $(0.0)$ & $(0.819)$ \\
& 0.9596 & adj. $R^{2}$ & 0.9546 & 0.9907 \\
\hline
\end{tabular}

The restoration of the water supply to disrupted HHs after the NGTC earthquake in 2004 (data in Table A3 in the Appendix) is shown in Figure 15 (refer to MHLW (2004)). It can be seen that approximately 125,000 HHs experienced water supply disruption on the day of the earthquake; however, the restoration process started the day after the earthquake, and water service was restored to all of the disrupted HHs after one month. To apply the approximation function, we can conclude that the period from D1 to D41 should be split into two sub-periods, as these exhibit very different behaviour: the initial sub-period shows a drastic decreasing trend, while the trend in the later period is extremely slow and stable. We have established that the first two weeks or so are very important for maximising the speed of the restoration process. Thus, two sub-periods are designated as follows: the former comprises D1 through D14, and the latter comprises D14 through D41. Then, the approximation functions are determined separately, as shown in Figure 15. We assume an approximation function with an exponential form as follows:

$$
y=a \mathrm{e}^{b x} \quad a, b \text { : parameters. }
$$

By transforming Equation (15) into a logarithmic form, the following equation is obtained, which can be used to obtain estimated values of parameters $a$ and $b$. 


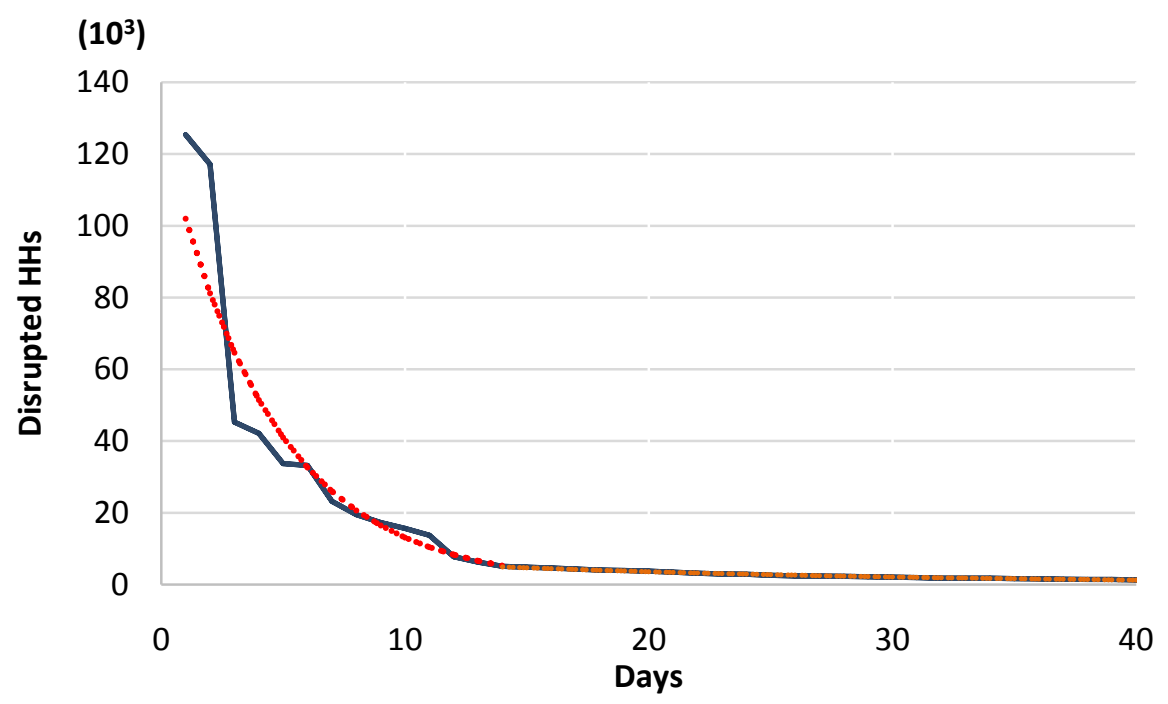

Figure 15. Water supply recovery process for disrupted HHs (NGTC) (Data adapted from [20] annexed in the Appendix).

$$
\ln y=\ln a+b x \quad a, b: \text { parameters }
$$

Applying the above approximation function, the actual values and estimated values (dotted segments) are shown in Figure 15. The regression results for the restoration of water after the NGTC earthquake are listed in Table 6.

The GEJE, which occurred on 11 March 2011, was one of the most powerful earthquakes in the history of Japan, with a seismic magnitude of 9.1 on the JMA scale. This earthquake caused severe damage to coastal prefectures such as Iwate, Miyagi, and Fukushima. Figure 16 shows the HHs with water disruption in these prefectures affected by the GEJE; the corresponding data are listed in Table A4 in the Appendix. In the trends in Figure 16, we can observe a bump in the restoration curves for all three prefectures approximately one month after the occurrence of the earthquake. This unusual phenomenon is due to the major aftershocks that affected six eastern coastline prefectures, mainly Iwate, Miyagi, and Fukushima. The magnitude of the aftershock on 7 April was 7.4, while the magnitude of that on 11 April 2011 was 7.1 (JMA scale). Figure 16 shows the overall trends of the water supply restoration in the three prefectures after the GEJE [15]. Figure 16 shows the water supply restoration after the GEJE for the three prefectures overall, which had a large number of disrupted HHs. It can be observed that approximately 60,000 $\mathrm{HH}$ sere experiencing water disruption even after three months. This is mainly a result of the two major aftershocks that occurred on 7 and 11 April, one month after the GEJE, and produced the tsunami that caused the nuclear disaster at the FDNPP. Soon after that incident, radiation was released into the atmosphere, which forced the government to evacuate the residents living within a radius of $20 \mathrm{~km}$ of the plant to avoid exposure to radiation.

To apply the approximation function, we can conclude that the period from D1 to D100 should be split into two sub-periods, as these periods exhibit very 


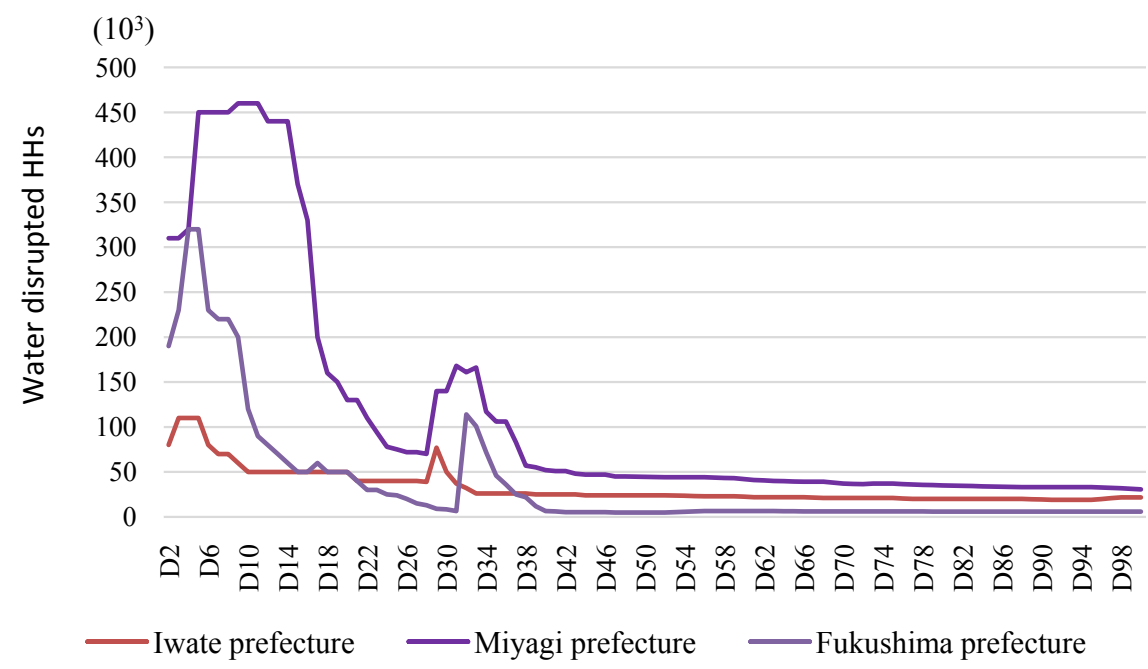

Figure 16. Water supply restoration process for disrupted HHs in Iwate, Miyagi, and Fukushima prefectures (GEJE) (Data was adapted from [15]).

different behaviour. Namely, the early sub-period shows a drastic decrease, while the trend in the later period is extremely slow and stable. We have established that the first two weeks or so are very important for maximising the speed of our recovery operation. Thus, two sub-periods are designated as follows: the former comprises D1 through D40, and the latter comprises D40 through D100. Then, the approximation functions are determined separately, as shown in Figure 17. We assume the approximation functions have the exponential form given in Equation (8). Applying the above approximation function, the actual values and estimated values (dotted segments) are shown in Figure 17. The regression results for the GEJE are listed in Table 7.

The data for the restoration of water utility services after the KMMT earthquake are given in Table A5 in the Appendix and plotted in Figure 18 (Government of Kumamoto (2016)). On the day of the earthquake, water supply services to more than $90,000 \mathrm{HHs}$ were disconnected; however, the restoration process started the day after the earthquake and water services were restored to all of the disrupted HHs after one month.

To apply the approximation function, we can conclude that the period from D3 to D62 should be split into two sub-periods, as these periods exhibit very different behaviour. Namely, the early sub-period shows a drastic decrease, while the trend in the later period is extremely slow and stable. We have established that the first two weeks or so are very important for maximising the speed of the restoration operation. Thus, two sub-periods are designated as follows: the former comprises D3 through D24, and the latter comprises D24 through D62. Then, the approximation functions are determined separately, as shown in Figure 18. We assume the approximation functions have the exponential form given in Equation (8). The parameter estimates obtained from the regression results for the KMMT earthquake are given in Table 7.

Many studies have been conducted in which the performance of water supply 
Table 7. Parameter estimates for water supply restoration models (GEJE, KMMT).

\begin{tabular}{|c|c|c|c|c|c|}
\hline E.Q. & \multicolumn{2}{|c|}{ GEJE } & E.Q. & \multicolumn{2}{|c|}{ KMMT } \\
\hline Model & \multicolumn{2}{|c|}{$y=a \mathrm{e}^{-b x}$} & Model & \multicolumn{2}{|c|}{$y=a \mathrm{e}^{-b x}$} \\
\hline Period & D1 - D41 & D41 - D100 & Period & D1 - D26 & D26 - D62 \\
\hline $\ln a$ & $\begin{array}{c}13.716 \\
(122.27) \\
(0.0)\end{array}$ & $\begin{array}{c}11.514 \\
(979.33) \\
(0.0)\end{array}$ & $\ln a$ & $\begin{array}{c}11.601 \\
(83.305) \\
(0.0)\end{array}$ & $\begin{array}{c}9.8987 \\
(46.833 \\
(0.0)\end{array}$ \\
\hline$b$ & $\begin{array}{c}-0.05495 \\
(-11.628) \\
(0.0)\end{array}$ & $\begin{array}{c}-0.00592 \\
(-36.255) \\
(0.0)\end{array}$ & $b$ & $\begin{array}{c}-0.1716 \\
(-19.802) \\
(0.0)\end{array}$ & $\begin{array}{c}-0.1243 \\
(-26.618) \\
(0.819)\end{array}$ \\
\hline $\operatorname{adj} \cdot R^{2}$ & 0.7793 & 0.9563 & $\operatorname{adj} . R^{2}$ & 0.9445 & 0.9516 \\
\hline
\end{tabular}

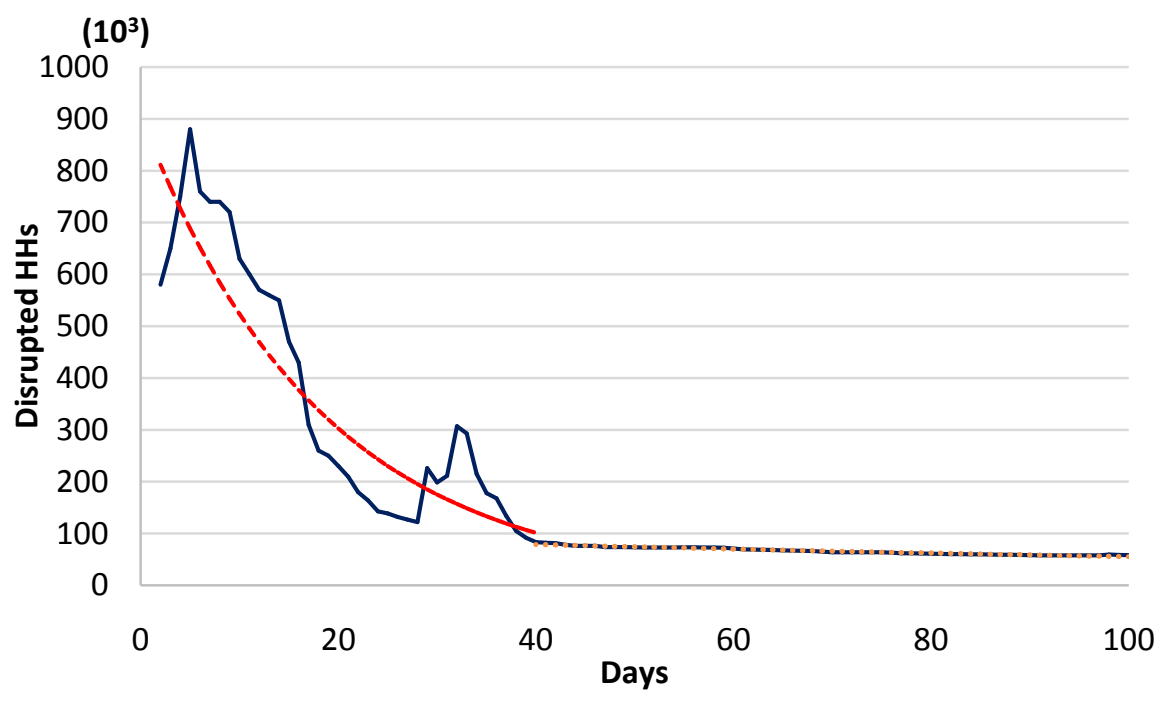

Figure 17. Water supply restoration process for disrupted HHs (GEJE) (Data adapted from [15] annexed in Appendix).

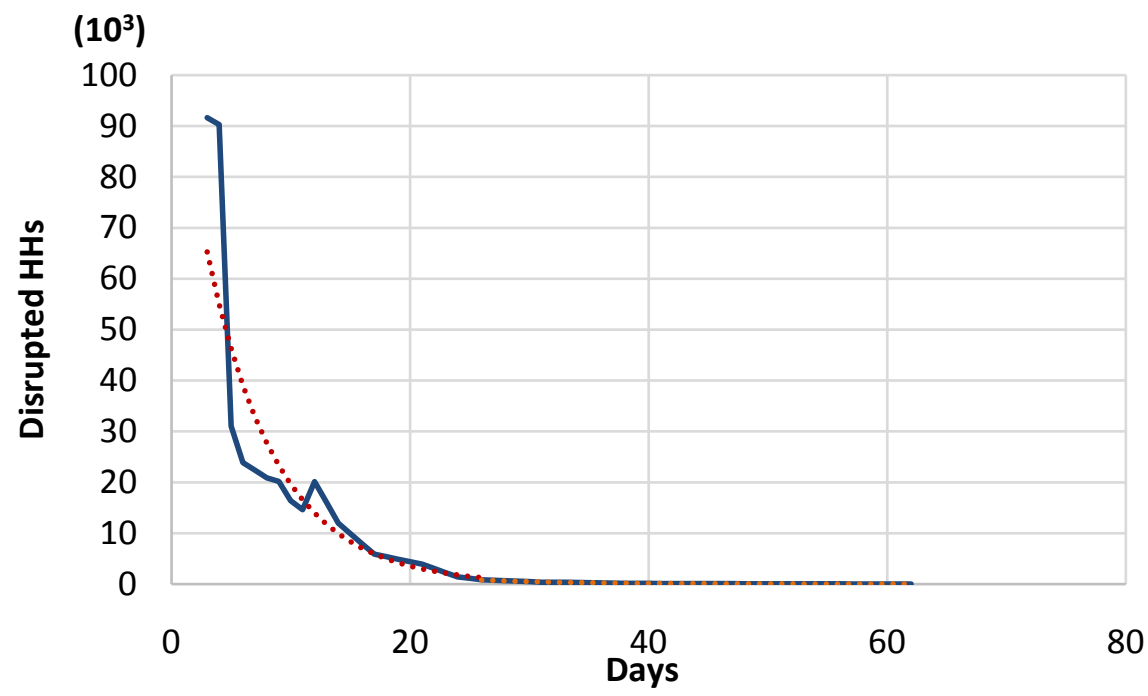

Figure 18. Water supply restoration process for disrupted HHs (KMMT) (Data adapted from the Kumamoto prefectural government webpage). 
systems is measured by defining performance indicators (PIs) using actual data. PIs were used to assess the performance of a water supply system in terms of its efficiency and effectiveness. PIs are tools for evaluating the efficiency, effectiveness, and robustness of water supply systems, and they can help decision-makers develop safe and reliable infrastructure strategies based on past and present trends [21] (see also [22] [23] [24]). The PI system in Japan consists of an excessive number of items, and principal component analysis was used to reduce the dimensionality of the original data [25]. They emphasised the importance of establishing PIs, as an adequate supply of safe and high-quality water is the basic purpose of any water supply utility, and noted that the ultimate purpose of PIs is to provide information for decision-makers rather than for statistical evaluation.

\section{Summary and Conclusions}

We adopted a quantitative methodology to investigate the evacuation situation and recovery process after recent severe natural disasters in Japan. The analysis focused on three aspects: data on evacuees and evacuation centres; the restoration process for public utilities such as electricity, water, gas, and telecommunication lines in large urban areas; and the restoration of the water supply system. Analysis of the evacuation situation revealed that the relationship between EVCN and EVCU could be expressed by a polynomial function for each of the HNSA, NGTC, and KMMT earthquakes, as indicated in Table 2. Collectively, in these three cases (excluding the GEJE), this relationship was given by a quadratic function passing through the origin, as listed in the TOTAL column in Table 2. We also found that the data for the exceptional case of a huge, unusual, and unprecedented earthquake (the GEJE) approached the approximation curves given for the other three earthquakes as a quadratic function after three months. In the case of the GEJE, however, we know that the evacuation situation was different from that in the other cases because the GEJE resulted in the nuclear disaster at the FDNPP following the earthquake and subsequent tsunami.

We investigated the restoration processes for public utilities such as electricity, water, gas, and telecommunication lines using the data for the HNSA earthquake. The results showed that the electricity and telecommunication systems were restored within one or two weeks, whereas the restoration of gas lines and the water supply could require more than three months. We found that the restoration processes of social infrastructure could be divided into two types. The first group consists of electricity and water, which exhibit convex restoration process curves, while the second group includes the gas supply and communication lines, which take the form of a concave function or a concave function following a convex curve. From the viewpoint of natural disaster mitigation policy, this implies that for electricity and water systems, increasing the slope of the approximate decreasing curve is important, while for gas and communication lines, shortening the initial flat period before the decreasing part of the curve is more important. In addition, with regard to the recovery of gas lines, we found 
that in addition to shortening the flat stagnant period before starting the decrease, obtaining a greater rate of decrease is also a significant and necessary measure.

The recovery trends for the water supply system after large-scale earthquakes reveal that water supply systems require longer periods of restoration than other public utilities. We found that a log-linear function could best describe the water restoration after the occurrence of the HNSA earthquake. Regarding the water supply restoration for the NGTC, KMMT, and GEJE, exponential functions could best fit the actual data. Here, in applying approximation functions to the water supply recovery process, we found that the restoration period should be split into two sub-periods with very different behaviour, as given in Table 6 and Table 7. Specifically, the early sub-period is characterised by a drastic decrease, while the trend in the later period is extremely slow and stable. This implies that from the perspective of natural disaster mitigation policy, obtaining a greater rate of decrease in the first period is effective and important.

Finally, we believe the approaches discussed in the present study will contribute to the development of effective mitigation policies for natural disaster preparation in Japan.

\section{Conflicts of Interest}

The authors declare no conflicts of interest regarding the publication of this paper.

\section{References}

[1] Rose, A. (2007) Economic Resilience to Natural and Man-Made Disasters: Multidisciplinary Origins and Contextual Dimensions. Environmental Hazards, 7, 383-398. https://doi.org/10.1016/j.envhaz.2007.10.001

[2] EM-DAT (2020) The International Disaster Database by Centre for Research on the Epidemiology of Disaster (CRED). Earthquakes and Japan, Facts and Details. http://factsanddetails.com/japan/cat26/sub160/item866.html

[3] Parwanto, N.B. and Oyama, T. (2014) A Statistical Analysis and Comparison of Historical Earthquake and Tsunami Disasters in Japan and Indonesia. International Journal of Disaster Risk Reduction, 7, 122-141. https://doi.org/10.1016/j.ijdrr.2013.10.003

[4] MOFA Japan (2020) Disasters and Disaster Prevention in Japan. Ministry of Foreign Affairs, Japan. https://www.mofa.go.jp/policy/disaster/21st/2.html

[5] Government of Japan (2015) Estimation of the Amount of Damage of the Great East Japan Earthquake.

http://www.bousai.go.jp/2011daishinsai/pdf/110624-1kisya.pdf

[6] Parwanto, N.B. and Oyama, T. (2013) Investigating Major Factors to Affect Human Casualties of Natural Disasters and Reviewing Recovery Policies. Proceeding of the 11 th International Symposium on Operations Research \& Its Applications (ISORA 2013), Huangshan, 23-25 August 2013, 38-46. https://doi.org/10.1049/cp.2013.2254

[7] Parwanto, N.B., Morohosi, H. and Oyama, T. (2015) Applying Network Flow Optimization Techniques to Improve Relief Goods Transport Strategies under Emergency Situation. American Journal of Operations Research, 5, 95-111. 
https://doi.org/10.4236/ajor.2015.53009

[8] Parwanto, N.B. and Oyama, T. (2015) Investigating the Impact of the 2011 Great East Japan Earthquake and Evaluating the Restoration and Reconstruction Performance. Journal of Asian Public Policy, 8, 329-350. https://doi.org/10.1080/23307706.2015.1006764

[9] Murao, O. (2020) Recovery Curves for Housing Reconstruction from the 2011 Great East Japan Earthquake and Comparison with Other Post-Disaster Recovery Processes. International Journal of Disaster Risk Reduction, 45, 101467. https://doi.org/10.1016/j.ijdrr.2019.101467

[10] Zorn, C.R. and Shamseldin, A.Y. (2015) Post-Disaster Infrastructure Restoration: A Comparison of Events for Future Planning. International Journal of Disaster Risk Reduction, 13, 158-166. https://doi.org/10.1016/j.ijdrr.2015.04.004

[11] Barabadi, A. and Ayele, Y.Z. (2018) Post-Disaster Infrastructure Recovery: Prediction of Recovery Rate Using Historical Data. Reliability Engineering and System Safety, 169, 209-223. https://doi.org/10.1016/j.ress.2017.08.018

[12] Hayashi, H. (2010) Natural Disasters in Japan. In: Marquina, A., Ed., Global Warming and Climate Change. Energy, Climate and Environment Series, Palgrave Macmillan, London, 118-132. https://doi.org/10.1057/9780230281257_7 https://link.springer.com/chapter/10.1057/9780230281257_7

[13] Britannica (2020) Kobe Earthquake of 1995. https://www.britannica.com/event/Kobe-earthquake-of-1995

[14] Kobe City (2014) The Great Hanshin-Awaji Earthquake. https://www.city.kobe.lg.jp/safety/hanshinawaji/revival/promote/january.2014.pdf

[15] FDMA (Fire and Disaster Management Agency) (2011) Great East Japan Earthquake Related Information.

https://www.fdma.go.jp/disaster/higashinihon/higaihou-past-jishin/

[16] Niigata Prefectural Government (2007) Chuetsu-oki Earthquake Related Information: List of Past Evacuation Centers. https://www.pref.niigata.lg.jp/sec/kikitaisaku/1203526874115.html

[17] Government of Kumamoto (2016) About the Damage Situation to Affect Kumamoto Earthquake.

https://www.pref.kumamoto.jp.e.qp.hp.transer.com/kinkyu/pub/default.aspx??_id=9

[18] Reconstruction Agency (2020) Great East Japan Earthquake. https://www.reconstruction.go.jp/english/index.html

[19] Kobe City University (1996) Earthquake Disaster Library. http://www.lib.kobe-u.ac.jp/directory/eqb/book/4-367/

[20] MHLW (Ministry of Health, Labor and Welfare (2004) 2004 Niigata Prefecture Chuetsu Earthquake. https://www.mhlw.go.jp/houdou/2004/11/h1130-2.html

[21] Alegre, H. (1999) Performance Indicators for Water Supply Systems. In: Cabrera, E. and Garcla-Serra, J., Eds., Drought Management Planning in Water Supply Systems. Water Science and Technology Library, Springer, Dordrecht, Vol. 32, 148-178. https://doi.org/10.1007/978-94-017-1297-2_7 https://link.springer.com/chapter/10.1007/978-94-017-1297-2_7

[22] Akimov, A. and Simshauser, P. (2019) Performance Measurement in Australian Water Utilities. Current State and Future Directions. Research and Evaluation, 79, No. 1. https://doi.org/10.1111/1467-8500.12376

[23] Nudurupati, S.S., Bititci, U.S., Kumar, V. and Chan, F.T.S. (2011) State of the Art Literature Review on Performance Measurement. Journal of Computers and Indus- 
trial Engineering, 60, 279-290. https://doi.org/10.1016/j.cie.2010.11.010 https://www.sciencedirect.com/science/article/abs/pii/S0360835210002937?via\%3Di hub

[24] Nazif, S., Karamouz, M., Yousefi, M. and Zahmatkesh, Z. (2013) Increasing Water Security: An Algorithm to Improve Water Distribution Performance. Water Resources Management, 27, 2903-2921. https://doi.org/10.1007/s11269-013-0323-2

[25] Shinde, V.R., Hirayama, N., Mugita, A. and Itoh, S. (2013) Revising the Existing Performance Indicator System for Small Water Supply Utilities in Japan. Urban Water Journal, 10, 377-393. https://doi.org/10.1080/1573062X.2012.739628 https://www.tandfonline.com/doi/abs/10.1080/1573062X.2012.739628 


\section{Appendix}

Table A1. Restoration processes for water supply, gas, electricity, and communication lines (HNSA).

\begin{tabular}{|c|c|c|c|c|c|c|c|c|c|}
\hline Date & No. & Water & Gas $\left(10^{3}\right)$ & Electricity & Comm. line & Date & No. & Water & Gas \\
\hline $1 / 17 / 1995$ & & & & $2,600,000$ & 101,660 & $2 / 24 / 1995$ & 37 & 83,200 & 415.1 \\
\hline $1 / 18 / 1995$ & & & & 400,000 & 101,660 & $3 / 3 / 1995$ & 44 & 55,250 & 203.1 \\
\hline $1 / 19 / 1995$ & 1 & 495,300 & & 120,000 & 101,660 & $3 / 17 / 1995$ & 58 & 7800 & 73.359 \\
\hline $1 / 20 / 1995$ & 2 & 456,300 & 849.5 & 80,000 & 101,660 & $3 / 24 / 1995$ & 65 & 650 & 40.95 \\
\hline $1 / 21 / 1995$ & 3 & 393,250 & & 40,000 & 101,660 & $3 / 31 / 1995$ & 72 & 130 & 20.25 \\
\hline $1 / 22 / 1995$ & 4 & 384,800 & & 15,000 & 101,660 & 4/6/1995 & 78 & 130 & \\
\hline $1 / 23 / 1995$ & 5 & 373,100 & 855.9 & 0 & 92,160 & 5/7/1995 & 109 & & \\
\hline $1 / 24 / 1995$ & 6 & 367,250 & & & 92,160 & $5 / 8 / 1995$ & & & \\
\hline $1 / 25 / 1995$ & 7 & 359,450 & & & 81,160 & 5/9/1995 & & & \\
\hline $1 / 26 / 1995$ & 8 & 347,100 & & & 81,160 & $5 / 10 / 1995$ & & & \\
\hline $1 / 27 / 1995$ & 9 & 338,650 & 834.1 & & 61,660 & $5 / 11 / 1995$ & & & \\
\hline $1 / 28 / 1995$ & 10 & 321,100 & & & 48,660 & $5 / 12 / 1995$ & & & \\
\hline $1 / 29 / 1995$ & 11 & 302,900 & & & 31,660 & $5 / 13 / 1995$ & & & \\
\hline $1 / 30 / 1995$ & 12 & 286,650 & & & 15,660 & $5 / 14 / 1995$ & & & \\
\hline $1 / 31 / 1995$ & 13 & 267,800 & & & 0 & $5 / 15 / 1995$ & & & \\
\hline 2/3/1995 & 16 & 239,200 & 737.8 & & & $5 / 16 / 1995$ & & & \\
\hline 2/9/1995 & 22 & 168,350 & 644.8 & & & 5/17/1995 & & & \\
\hline 2/17/1995 & 30 & 138,450 & 529.9 & & & 5/18/1995 & & & \\
\hline
\end{tabular}

Table A2. Water disruption in overall Hyogo Prefecture (HNSA).

\begin{tabular}{cccc}
\hline Days after disaster & Disrupted households & Days after disaster & Disrupted households \\
\hline D1 & 953,720 & D15 & 415,000 \\
D2 & 953,720 & D16 & 405,000 \\
D3 & 842,220 & D17 & 325,000 \\
D4 & 800,000 & D18 & 315,000 \\
D5 & 660,000 & D19 & 305,000 \\
D6 & 650,000 & D20 & 290,000 \\
D7 & 632,940 & D30 & 178,000 \\
D8 & 620,000 & D40 & 100,000 \\
D9 & 610,000 & D50 & 29,000 \\
D10 & 590,000 & D60 & 6000 \\
D11 & 560,000 & D70 & 1000 \\
D12 & 530,000 & D80 & 90 \\
D13 & 500,000 & D90 & 1 \\
D14 & 472,800 & & \\
\hline & & &
\end{tabular}


Table A3. Water disruption in overall Niifgata Prefecture (NGTC).

\begin{tabular}{cccc}
\hline Days after disaster & Disrupted households & Days after disaster & Disrupted households \\
\hline D1 & 125,352 & D16 & 4615 \\
D2 & 117,106 & D17 & 4340 \\
D3 & 45,295 & D18 & 4030 \\
D4 & 42,122 & D19 & 3928 \\
D5 & 33,692 & D20 & 3751 \\
D6 & 33,216 & D22 & 3191 \\
D7 & 23,226 & D24 & 2889 \\
D8 & 19,512 & D26 & 2420 \\
D9 & 17,276 & D28 & 2279 \\
D10 & 15,668 & D30 & 2086 \\
D11 & 13,714 & D32 & 1796 \\
D12 & 7739 & D34 & 1781 \\
D13 & 6222 & D36 & 1583 \\
D14 & 5076 & D38 & 1451 \\
D15 & 4846 & D40 & 1302 \\
\hline
\end{tabular}

Table A4. Water disruption in 3 affected prefectures (GEJE).

\begin{tabular}{cccc}
\hline Days after disaster & Disrupted households & Days after disaster & Disrupted households \\
\hline D1 & 580,000 & D15 & 470,000 \\
D2 & 580,000 & D16 & 430,000 \\
D3 & 650,000 & D17 & 310,000 \\
D4 & 750,000 & D18 & 260,000 \\
D5 & 880,000 & D19 & 250,000 \\
D6 & 760,000 & D20 & 230,000 \\
D7 & 740,000 & D30 & 198,500 \\
D8 & 740,000 & D40 & 83,600 \\
D9 & 720,000 & D50 & 73,450 \\
D10 & 630,000 & D60 & 71,100 \\
D11 & 600,000 & D70 & 64,100 \\
D12 & 570,000 & D80 & 61,000 \\
D13 & 560,000 & D90 & 58,266 \\
D14 & 550,000 & D100 & 58,210 \\
\hline
\end{tabular}

Table A5. Water disruption in overall Kumamoto prefecture (KMMT).

\begin{tabular}{cccc}
\hline Days after disaster & Disrupted households & Days after disaster & Disrupted households \\
\hline D3 & 91,615 & D14 & 11,943 \\
D4 & 90,282 & D15 & 9912 \\
\hline
\end{tabular}




\section{Continued}

\begin{tabular}{llll}
\hline D5 & 31,018 & D16 & 7881 \\
D6 & 23,837 & D17 & 5849 \\
D7 & 22,365 & D18 & 5367 \\
D8 & 20,873 & D19 & 4885 \\
D9 & 20,154 & D20 & 4392 \\
D10 & 16,393 & D30 & 464 \\
D11 & 14,617 & D40 & 112 \\
D12 & 20,116 & D50 & 51 \\
D13 & 16,030 & D60 & 12 \\
D14 & 11,943 & D62 & 2 \\
D15 & 9912 & & \\
D16 & 7881 & & \\
D17 & 5849 & & \\
\hline
\end{tabular}

